\title{
Tratado del agua y la legislación peruana
}

\section{RESUMEN}

El artículo revisa la característica del agua, un recurso natural renovable, pero distribuido de forma irregular, que se ha convertido en un bien escaso para algunas poblaciones.

El acceso al agua potable es fundamental para la salud, uno de los derechos humanos básicos y un componente de las políticas eficaces de protección de la salud (OMS, 2006), tanto en el Perú como el mundo entero.

Palabras clave: ciclo hidrológico, calidad del agua, estándares nacionales de calidad ambiental del agua, características biológicas y microbiológicas

Treated Water AND PERUVIAN LegisLation

\section{ABSTRACT}

The article reviews the issue of water, a renewable natural resource, but unevenly distributed, which has become a rare commodity for some populations.

The access to clean water is essential to health, one of the basic human rights and a component of effective policies for the protection of health (WHO, 2006), both in Peru and the world.

Keywords: water cycle, water quality, national environmental quality standards water, biological and microbiological characteristics

\section{GENERALIDADES}

\subsection{Ciclo hidrológico}

La hidrología es el estudio del movimiento, distribución y calidad del agua en todas las zonas de la Tierra y se dedica tanto al ciclo hidrológico como a los recursos de agua [3].

La investigación hidrológica es útil en cuanto que permite entender mejor el mundo en el que vivimos, y también proporciona conocimientos para la ingeniería ambiental, política y planificación.

El agua en la Tierra se encuentra en tres estados: sólido como el hielo, nieve; líquido como el agua superficial y gaseoso como el vapor de agua. Océanos, ríos, nubes y lluvia están en constante cambio: el agua de la superficie se evapora, el agua de las nubes precipita, la lluvia se filtra por la tierra, etc. Sin embargo, la cantidad total de agua en el planeta no cambia. La circulación y conservación de agua en la Tierra se llama ciclo del agua.

El ciclo del agua o ciclo hidrológico o es el proceso de circulación del agua entre los distintos compartimentos de la hidrósfera. Se trata de un ciclo biogeoquímico en el que hay una intervención de reacciones químicas, y el agua se traslada de unos lugares a otros o cambia de estado físico. Ver la Figura 1.

Las fases según CEPIS (operación y mantenimiento de plantas, 2002) son:

- Precipitación.

- Evaporación.

- Escorrentía superficial.

- Infiltración.

- Flujo subterráneo. 


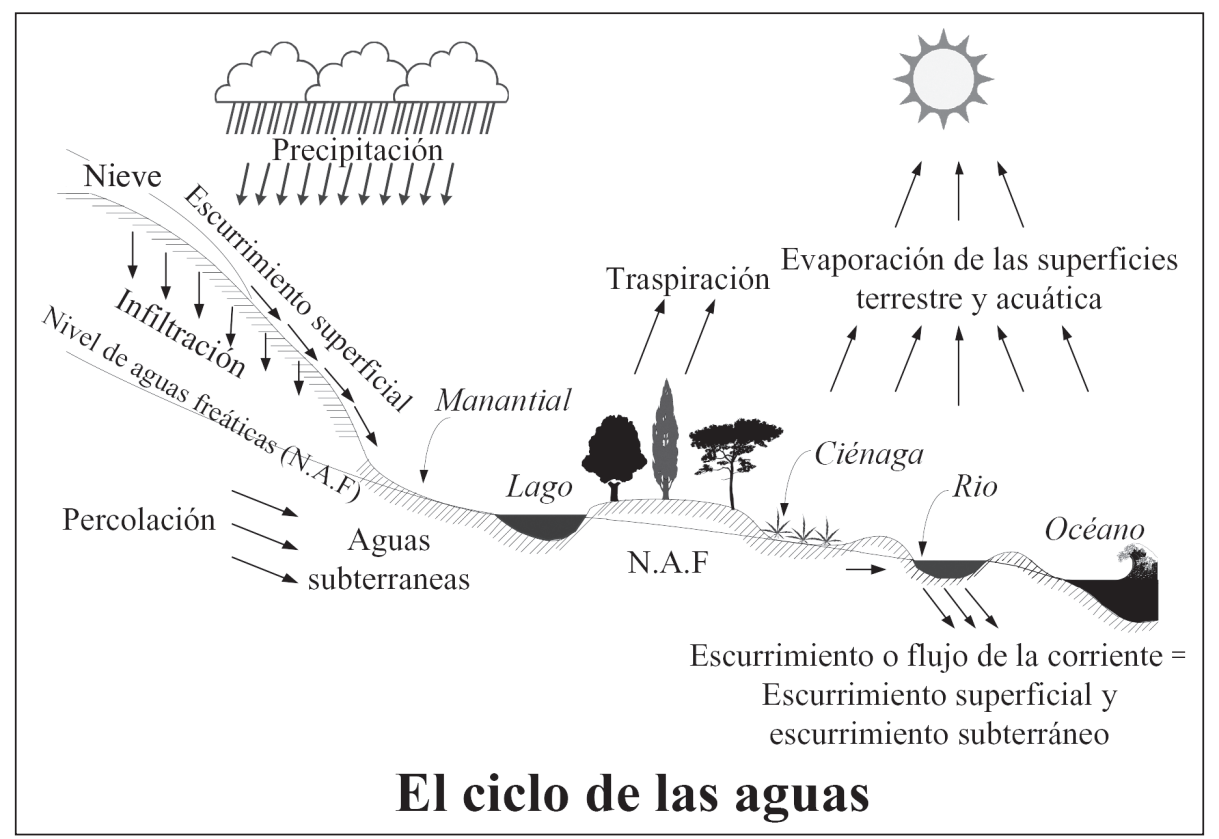

Figura 1. Ciclo hidrológico.

Fuente: Elaboración propia

Precipitación: Se produce cuando las gotas de agua que forman las nubes se enfrían acelerándose la condensación y uniéndose las gotitas de agua para formar gotas mayores que al llegar a las zonas frías, se condensan y terminan por precipitarse a la superficie terrestre en razón a su mayor peso. La precipitación puede ser sólida (nieve o granizo) o líquida (lluvia).

Evaporación: El agua se evapora en la superficie oceánica, sobre la superficie terrestre y también por los organismos, en el fenómeno de la transpiración en plantas y sudoración en animales. Los seres vivos, especialmente las plantas, contribuyen con un $10 \%$ al agua que se incorpora a la atmósfera.

Escorrentía superficial: Este término se refiere a los diversos medios por los que una parte de la lluvia que cae se desliza o escurre cuesta abajo por la superficie del terreno. En los climas no excepcionalmente secos, incluidos la mayoría de los llamados desérticos, la escorrentía es el principal agente geológico de erosión y de transporte de sedimentos.

Infiltración: Ocurre cuando el agua que alcanza el suelo, penetra a través de sus poros y pasa a ser subterránea. La proporción de agua que se infiltra y la que circula en superficie (escorrentía) depende de la permeabilidad del sustrato, de la pendiente y de la cobertura vegetal. Parte del agua infiltrada vuelve a la atmósfera por evaporación o, más aún, por la transpiración de las plantas, que la extraen con raíces más o menos extensas y profundas. Otra parte se incorpora a los acuíferos, niveles que contienen agua estancada o circulante. Parte del agua subterránea alcanza la superficie allí donde los acuíferos, por las circunstancias topográficas, intersecan (es decir, cortan) la superficie del terreno.

Flujo subterráneo: La escorrentía superficial proveniente de las lluvias, alimenta a los acuíferos y estos salen a la superficie a través de los manantiales y pozos.

Las aguas son pluviales, superficiales y subterráneas, atendiendo a la clasificación de las aguas naturales según el ciclo hidrológico.

Las pluviales deben su origen a las precipitaciones de lluvias, nieve y granizo. Las superficiales son: ríos, riachuelos, lagos naturales o artificiales, reservorios para almacenamiento, entre otros; y las subterráneas.

La capa que contiene agua subterránea se denomina acuífero; existiendo dos tipos de acuíferos: el freático y el artesiano. El primero se denomina cuando la capa superficial se encuentra a presión atmosférica o normal. El artesiano es el acuífero que se encuentra a una presión mayor que la atmosférica.

\subsection{Importancia del agua}

El agua es un recurso natural renovable, pero distribuido de forma irregular, se convierte en un 
bien escaso para algunas poblaciones. Se calcula que entre 220 millones de personas de países en vías de desarrollo carecen de una fuente de agua cerca de sus hogares. Además algunas fuentes estiman que el $90 \%$ de las aguas de deshecho de las ciudades de los países en desarrollo se descarga sin su respectivo tratamiento en ríos, lagos y cursos de aguas. Así más de 900 millones de personas al año sufren de enfermedades relacionadas con el agua insalubre.

El agua es indispensable para vivir, sin agua no hay vida. En un inicio el hombre se limitaba a usar el agua para subsistir; es decir como bebida o para preparar sus alimentos.

La importancia del agua estriba en los siguientes aspectos [4]:

1. Fuente de vida, porque en su ausencia no pueden vivir ni las plantas, ni los animales ni el ser humano.

2. Indispensable en la vida diaria:

- Uso doméstico: en la casa para lavar, cocinar, lavar ropa, entre otros.

- Uso industrial, como en la industria curtiembre, industria de alimentos, limpieza, generación de energía eléctrica, etc.

- Uso agrícola para irrigar los campos.

- Uso ganadero, para dar de beber a los animales domésticos.

- En la acuicultura, para la crianza de peces y otras especies.

- Uso medicinal, para curar enfermedades. Las aguas termales y medicinales son muy abundantes en el Perú.

La agricultura por ejemplo, necesita de recursos hídricos considerables, no exigiendo los mismos requerimientos de calidad del agua que tienen otros usos, como ocurre con el consumo doméstico e industrial. Por esa razón, a veces, es posible compatibilizar el suministro urbano con el agrícola en un mismo sistema de aprovechamiento hídrico.

Todos estos aspectos por acción del ser humano, han generado el aumento del consumo del recurso hídrico.

El agua es una sustancia compuesta de dos partes de hidrógeno y una de oxígeno (). El hidrógeno es el gas más abundante del universo, probablemente constituye $99 \%$ de toda su materia. El oxígeno, si bien es mucho menos común, representa gran parte de la corteza sólida de los planetas conocidos.
La vida está intrínsecamente relacionada con el agua. EI ADN, gigantesca molécula que constituye la base de todos los organismos conocidos, requiere, para su metabolismo y reproducción, estar en contacto con una solución acuosa de características apropiada [9].

Los contaminantes que contiene el agua lo hacen más importante que sus componentes. En una reacción química un rendimiento del $99.95 \%$ de pureza es un valor satisfactorio; pero en el caso del agua este nivel de impurezas es inaceptable. Para el agua, el nivel de insignificancia de los contaminantes normal en otras reacciones, puede echar a perder la calidad del producto y de sus usos [8]. Un ejemplo, la presencia de pequeñas partes de plomo como de 1 ppm (parte por millón), ocasionan que el agua sea inservible.

Cuando el agua entra en contacto con el aire, suelo, inclusive con el hombre, adquiere impurezas y modifica su composición, lo que ocasiona enfermedades y perjuicios al ser humano.

Según la Organización Mundial de la Salud (OMS), "Aproximadamente el $25 \%$ de las camas de los hospitales del mundo, están ocupadas por enfermos ocasionados por la calidad del agua" (CEPIS, operación y mantenimiento de plantas, 2002).

\section{CALIDAD DEL AGUA}

El agua pura no se encuentra en su forma natural, porque es un excelente solvente. Cuando el agua cae en forma de lluvia, las gotas disuelven los gases de la atmósfera (carbónico, oxígeno, entre otros) y transportan el polvo de la tierra. En el caso que arrastra gas carbónico de la atmósfera, se acidifica y se incrementan más sus propiedades solventes. Esta agua en el ciclo hidrológico pasa a ser escorrentía superficial, flujo subterráneo o evaporación.

\subsection{Influencia del ciclo hidrológico}

El agua en escorrentía superficial disuelve sales presentes en los minerales que encuentra a su paso. Tal como ocurre con los carbonatos de calcio, que debido a la acción del agua se transforman en bicarbonatos que se hacen solubles.

El agua o en contacto con material orgánico en descomposición, se acidifica; estas materias son en general de origen vegetal que liberan gas carbónico y otros gases, como el sulfhídrico, el amoniaco, entre otros. El catión con el carbonato como anión, produce el ácido carbónico. El gas sulfhídrico se transforma en sulfitos y sulfatos, y el amoniaco en nitratos y nitritos. 
El estado coloidal, es producto de la descomposición de la materia orgánica que liberan sustancias orgánicas coloreadas en contacto con el agua. Esto también ocurre con el hierro y el manganeso que producen color.

La característica de turbidez depende de la velocidad con que marcha el agua sobre la superficie de la tierra, transportando material en suspensión. Esta capacidad produce la característica antes mencionada.

El olor, gusto y color en los cuerpos de aguas es ocasionado por la gran variedad de organismos vivos, tales como las algas, protozoarios, etc.

El agua con su acción solvente, disuelve las sales de los minerales que encuentra a su paso, tales como el carbonato y compuestos de fierro.

La cantidad de materia orgánica que recibe el cuerpo receptor, está influenciada por las aguas residuales, debido a la gran cantidad de bacterias, patógenos en el caso de provenir de aguas residuales domésticas (ARD), o una gran variedad de productos químicos si provienen de aguas residuales industriales (ARI). Esto influye no sólo a las aguas superficiales, también a las subterráneas principalmente a la capa freática.

\subsection{Normativa nacional}

Según Guías para la calidad del agua potable de la OMS (2006):

"Las normas sobre el agua de consumo pueden diferir, en naturaleza y forma, de unos países o regiones a otros. No hay un método único que pueda aplicarse de forma universal. Es fundamental tener en cuenta las leyes vigentes y en proyecto relativas al agua, a la salud y al gobierno local, así como evaluar la capacidad para desarrollar y aplicar reglamentos de cada país. Los métodos que pueden funcionar en un país o región no necesariamente podrán transferirse a otros países o regiones. Es fundamental que cada país examine sus necesidades y capacidades".

La Constitución Política del Perú (1993), en su Artículo 2.- Derechos Fundamentales de la persona, "Toda persona tiene derecho" declara:

Inciso 22. A la paz, a la tranquilidad, al disfrute del tiempo libre y al descanso, así como a gozar de un ambiente equilibrado y adecuado al desarrollo de su vida.

En el CAPÍTULO II DEL AMBIENTE Y LOS RECURSOS NATURALES se encuentran los artículos 66 y 67.

\section{Artículo 66.- Recursos Naturales}

Los recursos naturales, renovables y no renovables, son patrimonio de la Nación. El Estado es soberano en su aprovechamiento.

Por ley orgánica se fijan las condiciones de su utilización y de su otorgamiento a particulares. La concesión otorga a su titular un derecho real, sujeto a dicha norma legal.

\section{Artículo 67.- Política Ambiental}

El Estado determina la política nacional del ambiente. Promueve el uso sostenible de sus recursos naturales.

La Ley General del Ambiente, Ley 28611, en su TÍTULO PRELIMINAR DERECHOS Y PRINCIPIOS y el artículo I declara:

\section{Artículo I.- Del derecho y deber fundamental}

Toda persona tiene el derecho irrenunciable a vivir en un ambiente saludable, equilibrado y adecuado para el pleno desarrollo de la vida, y el deber de contribuir a una efectiva gestión ambiental y de proteger el ambiente, así como sus componentes, asegurando particularmente la salud de las personas en forma individual y colectiva, la conservación de la diversidad biológica, el aprovechamiento sostenible de los recursos naturales y el desarrollo sostenible del país.

El Decreto Supremo DS-002-008-MINAM en su artículo I: Aprobación de los Estándares Nacionales de Calidad Ambiental para el Agua (ECA para el Agua), establece el nivel de concentración o el grado de elementos, sustancias o parámetros físicos, químicos y biológicos presentes en el agua, en su condición de cuerpo receptor y componente básico de los ecosistemas acuáticos, que no representa riesgo significativo para la salud de las personas y medio ambiente.

Los ECA para el agua, clasifican las aguas nacionales en cuatro categorías:

1. Categoría I: Poblacional y recreacional.

2. Categoría II: Actividades marino-costeras.

3. Categoría III: Riego de vegetales y bebidas de animales.

4. Categoría IV: Conservación del ambiente acuático.

La Ley de Recursos Hídricos, Ley 29338, promueve la mitigación de la contaminación de las aguas, ocasionada por los residuos de los pueblos y ciudades y de las actividades productivas, la industria, la minería, la agricultura, entre otras; así 
como también prevé la adopción de estrategias para la adopción a las consecuencias de la desglaciación o cambio climático, que afecta a los nevados que constituyen la reserva natural para las futuras generaciones (Texto de la Presentación en el documento de la Ley 29338).

En el Capítulo II de la Ley 29338 AUTORIDAD NACIONAL DEL AGUA (ANA) Artículos 14 al 16, se especifica al ente rector, las funciones del ANA y los recursos económicos.

\section{Artículo $14^{\circ}$. La Autoridad Nacional como ente rector}

La Autoridad nacional es el ente rector y la máxima autoridad técnico-normativa del Sistema Nacional de Gestión de los Recursos Hídricos. Es responsable del funcionamiento de dicho sistema en el marco de establecido en la Ley.

\section{Caracterización del agua}

El agua es una de las sustancias más difundidas y abundantes en el planeta Tierra, "se calcula que sólo los océanos y los mares contienen 324, estimándose de 6 a 7 en los casquetes polares, que representan aproximadamente el $97 \%$ de los recursos hídricos totales" (Fair, Geyer y Okun, 1990). Sólo el 0,26\% del agua existente en el planeta es fácilmente accesible para el consumo, donde una fracción importante sufre algún tipo de contaminación. Según la Organización Mundial de la Salud (OMS), más de 1,200 millones de personas consumen agua sin garantías sanitarias, lo que provoca entre 20,000 y 30,000 muertes diarias y gran cantidad de enfermedades.

El agua es un disolvente universal, que por su estructura molecular bipolar, se disuelven o se depositan todo tipo de materiales e impurezas a medida que recorre a través del ciclo hidrológico, por lo que no es posible encontrar agua pura en la naturaleza; estas impurezas le dan a cada porción de agua su composición química característica o calidad.

Algunas de estas sustancias pueden resultar beneficiosas e incluso imprescindibles para que animales y plantas puedan realizar muchas de sus funciones biológicas. El agua para beber debe estar libre de organismos patógenos, concentraciones químicas, impurezas y de cualquier tipo de contaminación que cause problemas para la salud humana. Cuando el agua se encuentra contaminada, es necesario realizar el tipo de tratamiento, adecuado a las características de la comunidad, para que pueda ser agua de consumo $\mathrm{y}$ otros usos.
La calidad del agua se mide en términos de sus características físicas, químicas y biológicas (ver Tabla 1).

Tabla 1. Características del agua

\begin{tabular}{|l|l|}
\hline Físicas & $\begin{array}{l}\text { Turbidez, Color, Olor, Sabor, } \\
\text { Temperatura, Sólidos, } \\
\text { Conductividad. }\end{array}$ \\
\hline Químicas & $\begin{array}{l}\text { pH, Dureza, Acidez, alcalinidad, } \\
\text { Fosfatos, sulfatos, Fe, Mn, } \\
\text { Cloruros, Oxígeno disuelto, } \\
\text { Grasas y/o aceites, Amoníaco, Hg, } \\
\text { Ag, Pb, Zn, Cr, Cu, B, Cd, Ba, As, } \\
\text { Nitratos, Pesticidas, DBO, DQO, } \\
\text { entre otros. }\end{array}$ \\
\hline $\begin{array}{l}\text { Biológicas y } \\
\text { Microbiológicas }\end{array}$ & $\begin{array}{l}\text { Algas, Hongos, Bacterias } \\
\text { (patógenos), Protozoarios } \\
\text { (patógenos), Helmintos } \\
\text { (patógenos), Coliformes fecales, } \\
\text { Coliformes totales. }\end{array}$ \\
\hline
\end{tabular}

Fuente: Elaboración propia

Las aguas poseen en su constitución una gran variedad de elementos biológicos desde los microorganismos hasta los peces. El origen de los microorganismos puede ser natural, es decir constituyen su hábitat natural, pero también provenir de contaminación por vertidos cloacales y/o industriales, como también por arrastre de los existentes en el suelo por acción de la lluvia.

Los parámetros fisicoquímicos que se analizan a las muestras provenientes de las descargas de agua residual en un sistema de tratamiento consideran entre otros: demanda bioquímica de oxigeno $\left(\mathrm{dbo}_{5}\right)$, demanda química de oxigeno (dqo), sólidos totales, sólidos sedimentables, sólidos suspendidos totales, sólidos totales volátiles nitritos, nitratos, fosfatos, coliformes fecales y totales y turbiedad, aunado con la medición in situ de los parámetros de $\mathrm{pH}$, temperatura, oxígeno disuelto y su correspondiente porcentaje (\%) de saturación.

\subsection{Características físicas}

Se miden en un agua los siguientes parámetros físicos: Turbiedad, Color, Olor, Sabor, Temperatura, los Sólidos Totales y la Conductividad específica.

\section{Turbidez}

La turbidez o turbiedad de una muestra de agua es la medida de la interferencia que presentan las 
partículas en suspensión al paso de la luz. Esto es causado por el lodo y a la arcilla de los suelos que conforman los lechos de los ríos, a las partículas orgánicas, a los organismos microscópicos y a cuerpos similares que se encuentran suspendidos en el agua se aplica a las muestras de aguas que tienen materia suspendida y coloidal que interfiere con el paso de la luz a través del agua.

Es una medida de la reducción de la intensidad de la luz que pasa a través del agua. La turbidez impide la fotosíntesis.

\section{Color}

Proviene de la disolución de materiales vegetales o minerales; debido a la presencia de materia orgánica en proceso de descomposición, como lignina y taninos; a óxidos de hierro, zinc y manganeso; a excretas de organismos vivos, algas verdes o verde-azules. El color está ligado a problemas de contaminación.

El color del agua es consecuencia de la presencia de sustancias orgánicas disueltas o coloidales.

\section{Olor y sabor}

En el agua todas las sustancias orgánicas pueden producir olor y sabor, de acuerdo a la concentración en que se encuentren. Las algas también producen olor y sabor. El cloro impide la proliferación de las algas.

Son comunes en la generación de olor y sabor: el ácido sulfhídrico: $\mathrm{H}_{2} \mathrm{~S}$, el cloruro de sodio o sal de cocina $\mathrm{NaCl}$, sulfatos de sodio y magnesio, entre otros.

\section{Temperatura}

Una corriente puede cambiar su temperatura por efectos climáticos naturales o por la introducción de desechos industriales.

La temperatura es importante porque actúa sobre procesos como la actividad biológica, la absorción de oxígeno, la precipitación de compuestos, la formación de depósitos, y por los cambios de viscosidad en los procesos de tratamiento, como desinfección por cloro, filtración, floculación, sedimentación y ablandamiento.

\section{Sólidos}

La materia sólida se clasifica a toda la materia (excepto el agua), contenida en los materiales líquidos.

Es necesario medir la cantidad de materia sólida contenida en una gran cantidad de sustancias líquidas y semilíquidas que van desde aguas potables, aguas residuales, residuos industriales y lodos producidos en los procesos de tratamiento.

Los sólidos totales, son los que permanecen como residuo después de haber secado a $103^{\circ} \mathrm{C}$. Es igual a la suma del material disuelto y el suspendido.

Se denomina sólidos suspendidos a los residuos no filtrable o material no disueltos. Los Sólidos disueltos son el residuo filtrable.

Los sólidos volátiles corresponden a lo que se pierde después de una calcinación a $600^{\circ} \mathrm{C}$. Se interpretan en términos de materia orgánica.

Los sólidos fijos corresponden al residuo después de la calcinación. Representan la materia inorgánica presente en la muestra estudiada. Ver la Figura 2.

\section{Conductividad}

La conductividad es una medida indirecta de la cantidad de sales o sólidos disueltos que tiene un agua natural. Los iones en solución tienen cargas positivas y negativas; esta propiedad hace que la resistencia del agua al flujo de corriente eléctrica tenga ciertos valores. Si el agua tiene un número grande de iones disueltos su conductividad va a ser mayor. Cuanto mayor sea la conductividad del agua, mayor es la cantidad de sólidos o sales disueltas en ella.

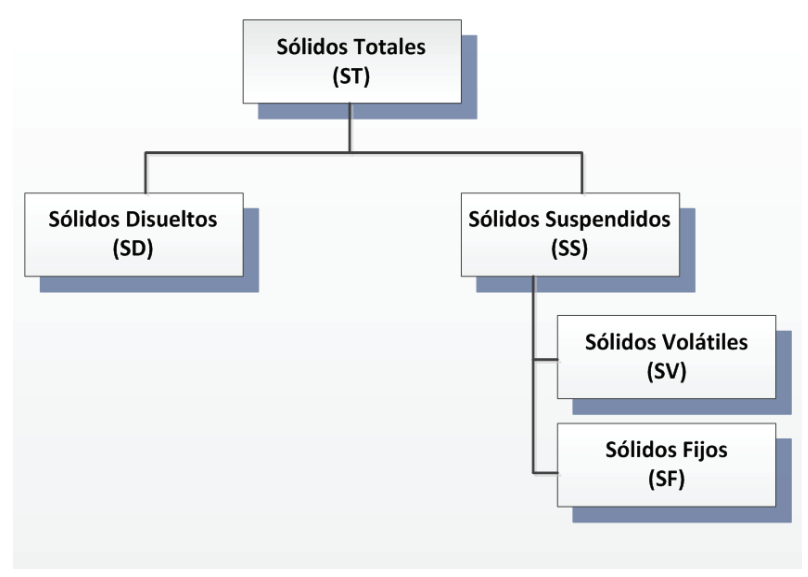

Figura 2. Sólidos Totales.

Fuente: Elaboración propia.

Como es rápido y relativamente fácil medir la conductividad de una muestra de agua, este parámetro de medición es muy empleado cuando se desea conocer la cantidad de sólidos totales disueltos (STD). Los STD, son el contenido de sales solubles que una muestra de agua en particular contiene. Una forma de conocer este valor, es 
filtrando el agua a través de una membrana de 0.2 micrones para retener los sólidos suspendidos y después de evaporar el filtrado se pesa y se tara para cuantificar estos sólidos gravimétricamente.

Esta forma de determinar los STD, requiere de tiempo, es una técnica analítica de alta precisión y está sujeta a errores si no se efectúa con los cuidados requeridos.

\subsection{Características químicas}

Los riesgos para la salud asociados a los componentes químicos del agua de consumo son distintos de los asociados a la contaminación microbiana y se deben principalmente a la capacidad de los componentes químicos de producir efectos adversos sobre la salud tras periodos de exposición prolongados. Pocos componentes químicos del agua pueden ocasionar problemas de salud como resultado de una exposición única, excepto en el caso de una contaminación masiva accidental de una fuente de abastecimiento de agua de consumo. La experiencia demuestra que en muchos incidentes de este tipo, aunque no en todos, el agua se hace imbebible, por su gusto, olor o aspecto inaceptables (OMS, Las Guías para la calidad del agua, 2006).

Según Guías para la calidad del agua, OMS (2006):

- Puede existir numerosos productos químicos en el agua de consumo; sólo unos pocos suponen un peligro inmediato para la salud en cualquier circunstancia. La prioridad a las medidas de monitoreo y de corrección de la contaminación del agua de consumo debe gestionarse de tal modo que se eviten utilizar innecesariamente recursos para el control de contaminantes químicos cuya repercusión sobre la salud sea pequeña.

- La exposición a concentraciones altas de fluoruro, de origen natural, puede generar manchas en los dientes $\mathrm{y}$, en casos graves, fluorosis ósea incapacitante. El agua de consumo puede contener arsénico de origen natural y una exposición excesiva al mismo puede ocasionar un riesgo significativo de cáncer y lesiones cutáneas. Otras sustancias de origen natural, como el uranio y el selenio, pueden también ocasionar problemas de salud cuando su concentración es excesiva.

- La presencia de nitratos y nitritos en el agua se ha asociado con la metahemoglobinemia, sobre todo en lactantes alimentados con biberón. La presencia de nitratos puede deberse a la aplicación excesiva de fertilizantes o a la filtración de aguas residuales u otros residuos orgánicos a las aguas superficiales y subterráneas.

- Son pocas las sustancias cuya presencia en el agua de consumo suponga una contribución importante a la ingesta en términos de prevención de enfermedades. Uno de ellos, es el efecto potenciador de la prevención contra la caries dental del fluoruro del agua de consumo

La química del carbono es el fundamento de la química orgánica; su conocimiento es importante cuando se trata de sistemas de tratamiento biológicos, o en el tratamiento de los residuos industriales. Las medidas más comunes de la química del carbonato, son los ensayos de acidez y alcalinidad.

\section{$\mathrm{pH}$}

La calidad del agua y el $\mathrm{pH}$ son a menudo mencionados como un binomio. El $\mathrm{pH}$ es un indicador muy importante, porque determinados procesos químicos solamente pueden tener lugar a un determinado $\mathrm{pH}$.

$\mathrm{El} \mathrm{pH}$ es una medida de acidez o alcalinidad de una disolución. Con el examen de pH se consigue el indicador de acidez de una sustancia, determinando el número de iones libres de hidrógeno $(\mathrm{H}+)$ en una sustancia.

La acidez es una de las propiedades más importantes del agua. El agua disuelve casi todos los iones. El $\mathrm{pH}$ sirve como un indicador que compara algunos de los iones más solubles en agua.

El pH indica la concentración de iones hidronio $\left[\mathrm{H}_{3} \mathrm{O}^{+}\right]$ presentes en determinadas sustancias. El resultado de una medición de $\mathrm{pH}$ viene determinado por una consideración entre el número de protones (iones $\mathrm{H}+$ ) y el número de iones hidroxilo $(\mathrm{OH}-)$. Cuando el número de protones iguala al número de iones hidroxilo, el agua es neutra, entonces su pH es 7; el $\mathrm{pH}=7$ indica la neutralidad de la disolución (cuando el disolvente es agua). Una solución que tenga $\mathrm{pH}$ menor que 7 es ácida y mayor que 7 es básica.

El término fue acuñado por el químico danés $S$. P. L. Sorensen, quien lo definió como el opuesto del logaritmo en base 10 de la actividad de los iones hidrógeno. Esto es:

$$
p H=-\log \left[a_{H}\right]
$$

La alcalinidad de una solución se define como la capacidad para neutralizar ácidos o aceptar protones; o como la cantidad de ácido por litro que se requiere para disminuir el $\mathrm{pH}$ a un valor menor de 4.5 . 
La alcalinidad del agua es la medida de su capacidad para neutralizar ácidos, debido a la presencia de sales en las formas de bicarbonatos (también carbonatos e hidróxidos) y sales de ácidos débiles (como boratos, silicatos, nitratos y fosfatos). El bicarbonato en la química acuática es la que mayor contribuye a la alcalinidad. Dicha especie iónica y el hidróxido son particularmente importantes cuando hay gran actividad fotosintética de algas o cuando hay descargas industriales en un cuerpo de agua.

La alcalinidad en la mayor parte de las aguas naturales superficiales está determinada principalmente por la química del carbonato; es decir:

$$
\mathrm{HCO}_{3}-\mathrm{CO}_{3}=\mathrm{OH}^{-} \text {y } \mathrm{H}^{+}
$$

Los carbonatos y bicarbonatos presentes en los cuerpos naturales de agua dulce, tienen su origen en el desgaste y disolución de rocas en la cuenca que contienen carbonatos, como ocurre con la piedra caliza o carbonato de calcio. La disolución es por la acción de $\mathrm{CO}_{2}$ disuelto en el agua (constituido por el atmosférico y del material orgánico de los sedimentos). El $\mathrm{CO}_{2}$ reacciona con el agua para generar pequeñas cantidades de ácido carbónico, el cual disuelve entonces las rocas de carbonato en la cuenca, lo que a su vez contribuye a la alcalinidad del agua (ver figura 3 ).

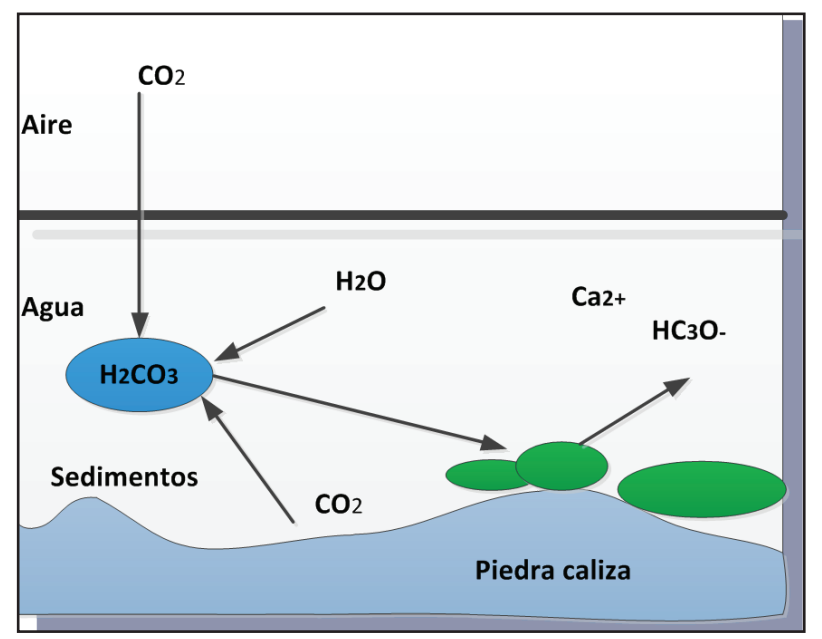

Figura 3. Origen de los carbonatos y bicarbonatos.

\section{Fuente: Elaboración propia.}

La alcalinidad se mide por valoración. Si el pH está por encima a 8.3 (la alcalinidad del hidróxido desaparece y solo se neutraliza la mitad de la alcalinidad de los carbonatos), la valoración se realiza en dos pasos: la primera utilizando el punto final de la fenolftaleína, y el naranja de metilo se utilizar para el segundo punto final.

La alcalinidad es necesaria para que se produzca desnitrificación en los procesos aeróbicos.

\subsection{Características biológicas y microbiológicas}

Los elementos patógenos son: virus, bacterias, protozoos y helmintos; y representan uno de los grandes problemas en calidad de agua que hay en el mundo, las bacterias provenientes de los excrementos humanos son causantes principales de la mortalidad infantil, y el agua es una de las vías de contagio más frecuentes.

\section{Algas}

Son organismos macro que viven sólo sobre la base de nutrientes inorgánicos y producen materia orgánica mediante fotosíntesis. Estos nutrientes son carbono, en forma de o bicarbonato; nitrógeno, generalmente en forma de nitrato; fósforo, en forma de fosfato; azufre como sulfato y trazas de los elementos sodio, potasio, calcio, magnesio, hierro, cobalto y molibdeno.

Se ha establecido que la vida en la tierra depende de la luz solar. Una parte muy pequeña de esta energía se utiliza en la fotosíntesis en las células de las plantas verdes, algas y cianobacterias para efectuar la biosíntesis de los componentes celulares. Esta biosíntesis, catalizada por la clorofila, es básicamente la transformación no espontánea del dióxido de carbono y agua en carbohidratos, representados por la glucosa $\left(\mathrm{C}_{6} \mathrm{H}_{12} \mathrm{O}_{6}\right)$ y oxígeno.

$$
6 \mathrm{CO}_{2}+6 \mathrm{H}_{2} \mathrm{O} \stackrel{\text { luz solar,clorofila }}{\longrightarrow} \mathrm{C}_{6} \mathrm{H}_{12} \mathrm{O}_{6}+6 \mathrm{O}_{2}
$$

En ausencia de luz, las algas metabolizan materia orgánica como la efectúan los organismos no fotosintéticos. Esto ocurre comúnmente en las noches, donde grandes cantidades de algas consumen oxígeno, agotando el oxígeno disuelto en el agua.

\section{Hongos}

Son microorganismos no fotosintéticos que poseen, por lo general, una estructura filamentosa. Considerando su alimentación son organismos heterotróficos, dado que requieren de materia orgánica como fuente de carbono. Son aeróbicos porque necesitan de oxígeno para su metabolismo. Su función en el ambiente es la ruptura de la celulosa de los hongos que secreta una enzima denominada 
celulosa, que es un catalizador biológico, el cual transforma la celulosa insoluble en carbohidratos solubles, que luego pueden ser absorbidos por la célula.

Los hongos no se desarrollan bien en el agua, más bien viven en el suelo donde junto con algunas bacterias producen el humus.

\section{Bacterias}

Las bacterias son seres de organismos unicelulares microscópicos. Se encuentran individualmente o se desarrollan formando colonias en grupos de hasta millones de células. Se pueden clasificar en bacterias beneficiosas para el ecosistema acuático, las cuales favorecen la auto depuración de los cuerpos del agua y las transformaciones orgánicas; y las bacterias patógenas las cuales pueden causar enfermedades graves en los seres vivos.

Las bacterias patógenas de transmisión hídrica provienen de seres humanos y animales de sangre caliente (animales domésticos, ganado, animales silvestres). En las zonas rurales la práctica de la defecación a campo abierto constituye una de las principales fuentes de contaminación de las aguas superficiales.

Las bacterias pueden ser aeróbicas, porque requieren oxígeno como aceptor de electrones:

$$
\mathrm{O}_{2}+4 \mathrm{H}^{+}+4 \mathrm{e}^{-} \rightarrow 2 \mathrm{H}_{2} \mathrm{O}
$$

También pueden ser anaeróbicas, que viven solo en ausencia de oxígeno, porque éste es tóxico para ella. Para su existencia se proveen de sustancias oxigenadas aceptoras de electrones, tales como el ion nitrato o sulfato. Las denominadas facultativas, utilizan oxígeno cuando está disponible, o sustancias oxigenadas cuando no está disponible.

\section{Protozoos}

Al igual que las bacterias, son organismos simples unicelulares, y se pueden clasificar en beneficiosas para el ecosistema acuático, con una proporción adecuada, ya que un incremento anormal puede ocasionar alteraciones; y los protozoos parásitos que pueden causar enfermedades.

Suelen estar presentes en aguas estancadas o en lagunas ubicadas en zonas de clima cálido. Su origen biológico es difícil de precisar, aunque se ha demostrado la presencia de algunos de ellos en el ganado y mamíferos pequeños como ratas, ratones, castores, chinchilla, entre otros.

\section{Helmintos}

Los helmintos son animales invertebrados, a los que se conoce usualmente como gusanos.

La infección se suele producir por la presencia de huevos de algunos grupos de helmintos en el agua y en las verduras. Para evitar la infección, se debe procurar que los huevos se desarrollen fuera del agua, a condiciones ambiente ya que es muy desfavorable para su desarrollo.

\section{Coliformes}

Para evaluar más ampliamente la calidad bacteriológica del agua se determina la presencia o ausencia de organismos coliformes. Los organismos patógenos están dentro del grupo de los coliformes, pero no todos los coliformes son patógenos, por lo que la presencia de coliformes en una muestra de agua no siempre indica la presencia de organismos causantes de enfermedad, sin embargo, para considerar un agua segura para beber o para actividades en las cuales el hombre tiene contacto íntimo con el agua, debe estar libre de organismos coliformes.

Los coliformes fecales (termotolerantes) son microorganismos con una estructura parecida a la de una bacteria común, la Escherichia coli y se transmiten por medio de los excrementos. Coliforme significa con forma de coli, refiriéndose a la bacteria principal del grupo, la Escherichia coli, descubierta por el bacteriólogo alemán Theodor von Escherich en1860.

Los coliformes son organismos indicadores de contaminación fecal, por las siguientes razones:

- Se encuentran en el intestino del hombre y de los animales de sangre caliente.

- Existen en las heces en una proporción de 300 millones por gramo de heces.

- Por su presencia en las aguas residuales, pueden ser rápidamente aisladas, en un agua recientemente contaminada por materia fecal.

Estas formas patógenas de Escherichia y de otras bacterias: Klebsiella, Enterobacter y Citrobacter (que por tener forma similar se denominan genéricamente coliformes fecales), se determinan por medio de la técnica descrita por McCrady (1915), el Número Más Probable (NMP) y actualmente sigue siendo ampliamente utilizada.

La ausencia de coliformes, es un indicador que el agua es potable desde el punto de vista microbiológico. 
Los Coliformes Fecales (CF) son un subgrupo de los Coliformes Totales (CT) donde también agrupa a los coliformes que no son de origen fecal. Los CF son capaces de fermentar la lactosa a $44^{\circ} \mathrm{C}$ en vez de $37^{\circ} \mathrm{C}$ como lo hacen los CT, de allí el nombre de Termotolerantes por su capacidad de resistir temperaturas más elevadas. La mayor especie en el grupo CF es el Escherichia coli.

$$
\mathrm{CT}=\mathrm{CNF}+\mathrm{CF}
$$

Ya que los CF se encuentran casi exclusivamente en las heces de los animales de sangre caliente, se considera que reflejan mejor la presencia de contaminación fecal; en cambio en aguas residuales los CF funcionan como una alerta de que ocurrió contaminación, sin identificar el origen. Indican que hubo fallas en el tratamiento, en la distribución o en las propias fuentes domiciliarias. Su presencia acciona los mecanismos de control de calidad y de procesamiento dentro de la planta de tratamiento de agua, e intensifica la vigilancia en la red de distribución.

En los ECA del Agua (Perú, 2008), se distinguen los parámetros microbiológicos: $\mathrm{CF}, \mathrm{CT}$, Enterococos fecales y Escherichia coli.

Tabla 2. Parámetros microbiológicos

\begin{tabular}{|l|c|c|}
\hline \multicolumn{3}{|c|}{ MICROBIOLÓGICO } \\
\hline $\begin{array}{l}\text { Coliformes Termotolerantes } \\
\left(44.5^{\circ} \mathrm{C}\right)\end{array}$ & $\mathrm{NMP} / 100 \mathrm{ml}$ & 0 \\
\hline Coliformes Totales $\left(35-37^{\circ} \mathrm{C}\right)$ & $\mathrm{NMP} / 100 \mathrm{ml}$ & 50 \\
\hline Enterococos fecales & $\mathrm{NMP} / 100 \mathrm{ml}$ & 0 \\
\hline Escherichia coli & $\mathrm{NMP} / 100 \mathrm{ml}$ & 0 \\
\hline
\end{tabular}

Fuente: ECA de agua (Perú, 2008) categoría 1

Los Enterococos han cobrado una gran importancia al nivel internacional por su elevada incidencia en las enfermedades nosocomiales y por la resistencia a muchos antimicrobianos. Son indicadores de la inocuidad de los alimentos. Igualmente, se encuentran dentro del grupo de microorganismos indicadores de contaminación fecal de las aguas, y se consideran como el indicador más eficiente para evaluar la calidad del agua de mar para uso recreativo.

Todos los Enterococos presentan alta tolerancia a condiciones ambientales adversas altas o bajas temperaturas, deshidratación, salinidad, luz solar, entre otros), por lo que son indicadores para determinar la contaminación fecal en aguas de baño marítimas, pues son las que mejor soportan esas condiciones de salinidad.

El análisis de Enterococos se realiza cuando se trata de aguas de bebida de calidad dudosa como son las muestras de pozos, es decir, aguas subterráneas o para aguas de recreación.

\section{DERECHO HUMANO BÁSICO}

El acceso al agua potable es fundamental para la salud, uno de los derechos humanos básicos y un componente de las políticas eficaces de protección de la salud (OMS, 2006).

El acceso al agua potable es prioritario en materia de salud y desarrollo en todos los ámbitos. Constatándose que las inversiones en sistemas de abastecimiento y saneamiento de agua son rentables desde el lado económico, comparado con la disminución de los efectos adversos para la salud y la consiguiente reducción de los costos de asistencia sanitaria.

Las enfermedades relacionadas con la contaminación del agua de consumo tienen una gran repercusión en la salud de las personas. Las medidas destinadas a mejorar la calidad del agua de consumo proporcionan beneficios significativos para la salud.

\subsection{En el Perú}

El 31 de marzo del 2009 se promulga la Ley de Recursos Hídricos (LRH), Ley N. ${ }^{\circ} 29338$, que deroga y reemplaza a la Ley General de Aguas. Luego de un año y como resultado de intensos debates y varias modificaciones, se promulgó el "Reglamento de la Ley de Recursos Hídricos", por Decreto Supremo N..$^{\circ}$ 001-2010 del 24 de marzo del 2010.

La LRH regula y garantiza el uso y gestión integrada del agua, a través de principios fundamentales, declara que el Agua constituye patrimonio de la Nación y que el dominio sobre ella es inalienable e imprescriptible, reafirmando que es un bien de uso público y su administración solo puede ser otorgaday ejercida para el bien común, la protección ambiental y el interés de la Nación. Es importante señalar que el objetivo estratégico de esta Ley es otorgar un uso racional, definiendo mecanismos apropiados para que el Estado, a través de la Autoridad Nacional del Agua (ANA), sea la autoridad del Sistema Nacional de los Recursos Hídricos del Perú.

La LRH, Ley N. ${ }^{\circ} 29338$ contempla un proceso de profunda reforma de la institucionalidad pública focalizándolo en la concertación de las entidades 
estatales involucradas en la gestión de los recursos hídricos.

Entre otros aspectos importantes, la presente Ley propicia el cambio en el modo de pensar y en las actitudes sobre el valor, uso y gestión del agua por todos los sectores sociales y productivos, en especial la agricultura, para que su aprovechamiento sea eficiente y productivo, poniendo especial interés en minimizar los impactos en los ecosistemas.

En el Perú existen tres vertientes hidrográficas: Pacífico, Amazonas y Titicaca. Cuenta con 159 Unidades hidrográficas, de las cuales 62 están en la vertiente del Pacífico, 84 en la vertiente del Amazonas y 13 en la vertiente del Titicaca. Estas Unidades Hidrográficas forman 14 ámbitos de las Autoridades Administrativas del Agua y 72 ámbitos de las Administraciones Locales de Agua, entidades descentralizadas de la Autoridad Nacional del Agua, órgano descentralizado del Ministerio de Agricultura (ANA, 2013).

La disponibilidad de agua en la vertiente del Pacífico es de $1.8 \%$, en el Titicaca de $0.5 \%$ y $97.7 \%$ en el Amazonas. Para una población que se distribuye en $70 \%$ concentrado en la vertiente del Pacífico, $26 \%$ en la vertiente del Amazonas y el $4 \%$ en la vertiente del Titicaca (ANA, 2013).

Según la ANA, "Uno de los problemas más importantes que afectan la disponibilidad $y$ demanda del agua, es el rápido crecimiento de la población y la migración de la misma hacia las ciudades costeras, en busca de un mejor porvenir".

\subsection{En el mundo}

La Organización Mundial de la Salud (OMS), continúa trabajando sobre la importancia del agua, el saneamiento y la higiene para la salud.

Los documentos finales de diversos foros internacionales sobre políticas relativas a la salud y el agua, entre los que destacan: La Conferencia Internacional sobre Atención Primaria de Salud en Alma Ata, Kazajstán ex Unión Soviética (1978), la Conferencia Mundial sobre el Agua de Mar del Plata (Argentina, 1977), iniciadora del Decenio Internacional del Agua Potable y del Saneamiento Ambiental, así como los Objetivos de Desarrollo del Milenio aprobados por la Asamblea General de las Naciones Unidas (ONU, 2000) y como el documento final de la Cumbre Mundial sobre el Desarrollo Sostenible de Johannesburgo de 2002.

La Asamblea General de las Naciones Unidas declaró el periodo de 2005 a 2015 como Decenio Internacional para la Acción "El agua, fuente de vida".
Según Guías para la calidad del agua potable (2006):

- Los peligros microbianos siguen siendo la principal preocupación en todos los países del mundo. La experiencia ha demostrado asimismo el valor de la aplicación de un método sistemático para garantizar la inocuidad microbiana.

- Existen sustancias químicas que no se habían tenido en consideración.

- La experiencia ha demostrado asimismo la necesidad de reconocer las importantes funciones que desempeñan numerosas organizaciones interesadas en la garantía de la inocuidad del agua de consumo.

- Es prioritario la aplicación de instrumentos y métodos para apoyar la gestión segura de los grandes sistemas de abastecimiento de agua entubada (por tuberías).

- El interés por los peligros derivados de la presencia de sustancias químicas en el agua de consumo sigue en aumento. La exposición del agua de consumo a unas pocas sustancias químicas como el fluoruro, el arsénico y el nitrato producen grandes efectos sobre la salud; y sustancias, como el plomo, el selenio y el uranio pueden producir también efectos significativos en determinadas condiciones.

\section{CONCLUSIONES}

1. El agua es indispensable para vivir, sin agua no hay vida. En un inicio el hombre se limitaba a usar el agua para subsistir; es decir como bebida o para preparar sus alimentos.

2. La vida está intrínsecamente relacionada con el agua.

3. El agua pura no se encuentra en su forma natural, porque es un excelente solvente.

4. La cantidad de materia orgánica que recibe el cuerpo receptor, está influenciada por las aguas residuales, debido a la gran cantidad de bacterias, patógenos en el caso de provenir de $A R D$, o una gran variedad de productos químicos si provienen de ARI.

5. La Ley de Recursos Hídricos, Ley 29338, promueve la mitigación de la contaminación de las aguas, ocasionada por los residuos de los pueblos y ciudades y de las actividades productivas, la industria, la minería, la agricultura, entre otras; así como también prevé la adopción de estrategias para la adopción 
a las consecuencias de la desglaciación o cambio climático, que afecta a los nevados que constituyen la reserva natural para las futuras generaciones.

6. Los riesgos para la salud asociados a los componentes químicos del agua de consumo son distintos de los asociados a la contaminación microbiana y se deben principalmente a la capacidad de los componentes químicos de producir efectos adversos sobre la salud tras periodos de exposición prolongados.

7. La LRH regula y garantiza el uso y gestión integrada del agua, a través de principios fundamentales, declara que el Agua constituye patrimonio de la Nación y que el dominio sobre ella es inalienable e imprescriptible, reafirmando que es un bien de uso público y su administración sólo puede ser otorgada y ejercida para el bien común, la protección ambiental y el interés de la Nación.

\section{REFERENCIAS BIBLIOGRÁFICAS}

1. Autoridad Nacional del Agua (2013). Atlas de Recursos Hídricos del Perú. Lima: Perú, ANA, Oficina del Sistema Nacional de Información de Recursos Hídricos.

2. Fair, R., Geyer, I. y Okun, N. (1990). Abastecimiento de aguas y remoción de aguas residuales. México, D.F.: México, Editorial Limusa S.A de C.V.

3. Hidrología. http://www.ciclohidrologico.com/ hidrologa, visitado el 25 de agosto de 2013.

4. perúecológico.com. http://peruecologico.com. pe/lib_c17_t02.htm , visitado el 25 de agosto de 2013.

5. CEPIS (2002). Operación y mantenimiento de plantas de tratamiento de aguas: Manual de capacitación para operadores. Lima: Perú, Centro Panamericano de Ingeniería Sanitaria y Ciencias del Ambiente.

6. Programa EXPLORA (2010). http://www. explora.cl/otros/agua/ciclo2.html , visitado el 25 de agosto de 2013.

7. OMS (2006). Guías para la calidad del agua potable. Genéve: Suiza, Ediciones de la Organización Mundial de la Salud, Volumen 1.

8. Russell, D. (2012). Tratamiento de Aguas Residuales: Un enfoque práctico. Barcelona: España, Editorial Reverté S.A.

9. Sequía en un mundo de agua (edición en línea). http://tierra.rediris.es/hidrored/ebooks/sequia/ cap01.html, visitado el 25 de agosto de 2013.

10. Ciclo del agua. http://es.wikipedia.org, visitado el 26 de agosto de 2013. 